\title{
El espacio: discursos y representaciones
}

\author{
Fecha de recepción:01/03/2010 - Aprobación:05/04/2010
}

\section{Harvey Murcia Quiñones}

\section{Resumen}

Este artículo analiza el discurso del periódico amarillista

El Espacio. El autor da cuenta del lenguaje que utiliza el diario para apelar a las audiencias populares y examina su contenido semiótico. El estudio considera los elementos narrativos del diario para desarrollar una reflexión sobre el discurso periodístico no tradicional y su incidencia.

\section{Palabras claves}

Cultura popular, fotografía periodística, lenguaje periodístico, medios masivos de comunicación, prensa, semiótica.

\begin{abstract}
This article analyzes the discourse of the sensationalist newspaper El Espacio. The author reports the language the newspaper uses to appeal to popular audiences and examines its semiotic content. The study takes into account the narrative elements of the newspaper in order to develop a reflection on non-traditional journalistic discourse and its impact.
\end{abstract}

\section{Keywords}

Journalistic language, journalistic photography, mass media, popular culture, press, semiotics.

\section{Introducción}

¿Qué define estos nuevos tiempos? Diría que la crisis. Es una constante de la manera como nos contamos y nos descubrimos; es la lógica con la que construimos nuestra memoria. La crisis se convierte en el paradigma explicativo de lo contemporáneo en tanto forma cambiante que determina nuevas concepciones del espacio y el tiempo. Por ello la crisis encierra las pistas para la com- prensión de este presente huidizo y de un futuro, tal vez, más incierto.

Acercarse a la crisis es acercase a los múltiples tiempos y las discontinuidades; es escribir las fracturas políticas y los reordenamientos sociales; escribir sobre la crisis es entrar en el escenario de las fragmentaciones sociales y la emergencia de una nueva comunicación que responde a las dinámicas de una sociedad en permanente cambio. Dicho cambio puede ser 
comprendido como el escenario de los significantes vacíos.

Definir significantes vacíos como "crisis" y "ruptura”, permitirá que nos deslicemos por aventuras de significación que sustenten la manera de acercarnos. Así, la crisis que vivimos hoy debe ser comprendida como una transformación en lo político,

Deesta manera, se establece un océano de sistemas sígnicos en la cultura, en la medida en que los colectivos mediante formas significantes construyen relatos para acercarse, para contarse, para explicarprocesos sociales, que determinan acciones $y$ comportamientos. en lo jurídico, en la narración; es comprender otras aceleraciones que se mueve en los múltiples tiempos, matrices irregulares que giran más o menos rápido según los procesos de los sujetos del acto de la comunicación. Pensar en los significantes vacíos no es solo pensar en microhistorias, es pensar y comprender otros procesos, otras circulaciones de los relatos en los que se contaba esa historia.

De esta manera, se establece un océano de sistemas sígnicos en la cultura, en la medida en que los colectivos mediante formas significantes construyen relatos para acercarse, para contarse, para explicar procesos sociales, que determinan acciones y comportamientos. De allí emerge ese sistema simbólico que explica cómo las comunidades han tejido su red social por donde circula "o procede la actividad productiva, transmisora y receptora de formas simbólicas significativas" (Thompson 1998:35).

Se podría realizar una búsqueda de las crisis en cualquier producción significante,

\section{Reseña de autor \\ Harvey Murcia Quiñones}

(Politécnico Grancolombiano)

hmurciaq@poligran.edu.co

Profesional en Lingüística, profundización en Comunicación Universidad Nacional de Colombia; especialista en Televisión de la Pontificia Universidad Javeriana, estudiante de maestría en Comunicación de la Pontificia Universidad Javeriana. Docente de tiempo completo del departamento de Comunicación Politécnico Grancolombiano. en cualquier material simbólico, en cualquier práctica social establecida, (piénsese en estatuas o placas, en los nombres de las avenidas o en canciones rancheras, boleros, en el cine). Pero aquí se pretende hacer una búsqueda en lo impreso, desde lo circulante en la no hegemonía, en el periódico El Espacio; elaborar una búsqueda de hacer historia y comunicación, de hacer surgir sentidos desde procesos difusos, llenos de opacidades y complejidades que porta el periódico.

El periódico El Espacio es un medio de comunicación en el cual circula la información que permite a una sociedad reconocerse. Sin embargo, quisiera otorgarle a El Espacio un estatuto diferente. Puede ser comprendido como un objeto mediante el cual circulan las formas simbólicas con las que las personas tejen sus referentes y sus constelaciones de sentido. El periódico es un archipiélago en el océano de la comunicación, es la irrupción de otros modos de comprender y vivir, de laborar e imaginar; propone estereotipos, referentes corporales, estrategias de acercamiento social y mercantil mediante materiales significantes dotados de sentido. Es un espejo en el que se pueden reconocer y descifrar las reconfiguraciones de lo social, de la ruptura. Es un espacio para los encuentros con el pasado, el devenir y el presente por medio de la narración.

Al mismo tiempo, el periódico permite establecer relaciones simbólicas, narrativas y contextuales entre quienes producen y consumen esos relatos: hay algo de nosotros en ellos, por ello la sospecha de la familiaridad, de la cercanía simbólica. Esto articula una legitimidad para el reconocimiento y su verosimilitud. Es así como el periódico El Espacio 
se acerca a las prácticas sociales donde toman sentido y se hacen tangibles las identidades y representaciones, las lógicas de control social, poder en el sentido "Foucoaultiano" y maneras de contar la cotidianidad para un sector social; redes dotadas de códigos que alteran y amplían nuestras nociones de mundo y nos ofrecen marcos de interpretación pragmática que remiten a una dialéctica permanente entre los objetos, las redes y los sujetos sociales, es lo que inunda al periódico.

Allí, en ese encuentro de varios códigos, se condensan unas fuerzas (tensiones) que descifran los dispositivos con los cuales se representa, se inventa lo social. Ya lo expresaba Baudrillard "a través de lo impreso, de la imagen y de la publicidad masiva la sociedad se exhibe y consume su propia imagen".

Entonces, la publicidad se puede explicar como un modo dominante de ver las lógicas de producción con el cual la sociedad se define, se construye y se legitima, espacio donde se absorben los valores sociales y se regresa al individuo al consenso social. Es el lugar para encontrar las marcas de las tensiones políticas, económicas y culturales; es la ventana donde puedo dejar-hacer ver las prácticas propias de representación.

\section{Contextualización}

Tomo en mis manos un periódico de esos que las personas llaman "oficiales”, miro atentamente su contenido, sus imágenes, sus grandes titulares; luego, otro que encaja en el mismo sentido, lo observo. Poco a poco emerge un sentido único, una especie de extrañamiento al notar que las temáticas se repiten una y otra vez. ¿Por qué una lógica de ecolalia? Esa sensación de que lo dicho se escucha en todos los medios de comunicación. Enciendo la tele, lo leído en los periódicos se repite, las variaciones surgen en lo audiovisual. Me acerco al universo herciano, esas voces repiten en tonos muy irónicos, satíricos lo que he visto o leído en los medios mencionados.

Existe un solo sentido en todos ellos: esa sensación de lo dominante. Y como enuncié, en los periódicos las "buenas” noticias son sustentadas con fotografías, con imágenes que validan lo escrito; imágenes de cuerpos que parecen sacados de la publicidad o del deporte. Desde allí se construye un cuerpo, un cuerpo social mediático que consumimos de manera cotidiana. Al verlo emerge la pregunta por los otros cuerpos, por esos que vienen de los indígenas, de los afrodescendientes, de los mestizos, de la cultura popular.

En los periódicos “oficiales” no existen esos cuerpos, no hacen parte de los significantes vacíos que permiten la crisis de lo contemporáneo. Esos cuerpos están alejados del escenario mediático, y han sido exorcizados del escenario narrativo. Pero si han sido expulsados de este paraíso mediático, ¿en dónde habitan?, ¿en dónde se encuentran? Creo que la pista la daba ya el maestro Jesús Martín Barbero, cuando en su libro De los medios a las mediaciones (2006), expresaba un escenario en creciente cultural, un medio en donde confluían diversos códigos culturales. El periódico sensacionalista ha sido y será el escenario para encontrar esos cuerpos alejados del discurso periodístico dominante.

Por eso, al tomar el periódico sensacionalista El Espacio estableceré la manera cómo construye y narra los cuerpos.

Para establecer un ejercicio de resistencia contra los discursos oficiales. Puede parecer un poco irónico, pero en este ejercicio
Poreso, tomando el periódico sensacionalista El Espacio establecerá la manera cómo construye y narra los cuerpos. 
no quiero apelar a las estrategias moralistas o éticas del periódico, todo lo contrario, se trata de encontrar una tensión entre lo popular y lo ilustrado.

El punto de partida lo ha ofrecido el sicólogo Maturana al establecer que "la distancia entre la ilusión y la percepción no es la realidad sino la comunidad de observadores que

El cuerpo fotografiado del periódico debe ser visto

como una memoria que alimenta una historia que le da cuerpo y sentido al cuerpo, que mantiene vivo el territorio, el tiempo y el espacio. decide qué es real y lo que no lo es" (Piscitelli, 1998: 115). Esta cita permite, de entrada, validar que lo que se presenta en el periódico El Espacio se presenta sin duda alguna noticia, acontecimiento; ¿para quién? Para todos los lectores que han posicionado el periódico como el segundo más leído en Cundinamarca, con 70.000 ejemplares vendidos diariamente. Por otro lado, permite inferir que la manera en la que se construye el acontecimiento debe condensar los códigos con los cuales la comunidad de observadores reconoce una imagen (o una noticia) como referente de un objeto o porción de realidad.

Más que ver si la imagen periodística corresponde o no, o si la noticia es veraz o no, se analizarán los elementos que permiten a El Espacio entrar en diálogo con lo popular, evidenciando mecanismos de producción del cuerpo, cómo se reconoce y, por último, cómo se narra.

\section{Ruta para el periódico El Espacio}

Es necesario definir algunas categorías para descifrar los códigos que admiten la validación de las imágenes, en tanto la cultura debe ser comprendida como un contrato firmado entre creadores y consumidores, aportando una marca propia de nuestro mundo; al vivir según un imaginario generalizado, todo se transforma en imágenes.

Se conceptualiza el periódico, no como un informativo, sino como un texto narra- tivo de vinculación; esto quiere decir que el periódico convoca a los lectores a un ritual de conocimiento, desciframiento y representación de los mismos. En El Espacio emerge la configuración de una realidad al acercarse a una porción de la cultura que debe estar cerca de la comunidad que consume el periódico.

Ver en las imágenes un componente estético, por ello la imagen produce una suerte de experiencia que permite encontrar formas de visualizar lo estético de la realidad en una suerte de simulacro y fascinación; goce y encantamiento que vincula y hace del mirar un deslizamiento por los tejidos comunicativos del ver. Su carácter radica en la capacidad expresiva de volver todo acontecimiento en un hecho fotográfico.

Hay que introducir la categoría lingüística de "anclaje" como recurso de reducción polisémica, en tanto la fotografía periodística no escapa al orden de las imágenes; es decir, posee un océano de significaciones que deben reducirse para darle un sentido único y así esquivar posibles ambigüedades tanto en la producción como en el consumo.

El cuerpo fotografiado del periódico debe ser visto como una memoria que alimenta una historia que le da cuerpo y sentido al cuerpo, que mantiene vivo el territorio, el tiempo y el espacio. Es así como se pueden definir ritmos y ritualidades para comprender el pasado, reafirmar el presente y reconstruir el futuro, poniendo en diálogo la tradición con lo moderno para mantener vivas las dinámicas sociales. El cuerpo de El Espacio se convierte en una extensión de la sociedad, una manera de ver y entender esas dinámicas en las que oscilan las significaciones con las que se entra y se es ser. 
Metonimia hecha verbo, libertad y condensación, inscripciones con las que se leen las normatividades se rige y se organiza esa misma sociedad.

\section{Descripción de El Espacio}

Al coger en mis manos algunos de los periódicos de El Espacio, encuentro que en la primera página siempre hay un titular en rojo que acompaña dos imágenes, algunas ocupan la totalidad de la página otras no. De igual forma, la imagen principal está seguida de otra, que muestra a los fotografiados en escenarios diferentes, en otras circunstancias.

No existe un índice temático en la primera página como en otros periódicos. $\mathrm{Su}$ organización temática se encuentra en la parte superior izquierda y derecha de cada página. Estas son las secciones:

Judicial: se narran los acontecimientos de las muertes y penalizaciones de los actores sociales: “ ¡Lo matan por defender a un amigo!”, “¡Muerte en una taberna!”, “¡Disparaba a matar!”, son algunos de los titulares que aparecen en la sección.

Política: presenta las notas de orden político del debate contemporáneo, las cuales hacen parte de los discursos sociales cotidianos: "El palo no está para hacer cucharas", "Pirámides en el Congreso" "Reelección en 2010 se aprobaría".

Nacional: en esta sección se detecta una particularidad. Antes de cada titular aparece el nombre de una región, así se articula el contenido de la noticia con un contexto geográfico específico. "Risaralda. La ruta de Megabús”, "Antioquia. Red para ubicar refugiados”, "Bolívar. ¡Simposio marítimo contra el narcotráfico!", "Norte de Santander. Guerra contra el hampa".
Actualidad: en forma indistinta se publican notas de orden político, con salud, y vida social. "La emergencia social por pirámides": "Nuevo rico nuevo pobre", "Bancos con fama de usureros", "Bloque de fe", "La santa misa", "Una muñeca llamada Michelle".

Deporte: se dedica a la narración del deporte nacional: “ ¡La segunda será la vencida”, "No insista Maradona”, “¡Los árbitros lo tienen en la mira!”, “¡Cuadrangulares de infarto!".

Anuncios: cumple la función de avisos clasificados, pero aquí no se venden ni casas, ni autosymucho menosfincas o motos: "Solución inmediata de atrasos”; “¿Embarazada? Tratamiento inyectable", "Hermano Zauro", “'Tu pareja se fue?”; "Cacique bruja llanera para unir parejas", entre otros.

Varios: este apartado tiene como referente temático la sexualidad, es presentado por el título "Hablemos de sexo, por la doctora Flor Alba Pachón”. Esta sección busca resolver dudas de orden matrimonial por medio de consejos a problemas como impotencia sexual, violencia de pareja o eyaculación precoz. Otro temario es la oferta sexual, en donde se publicitan pastillas para el desempeño sexual, crecimiento del miembro viril, líneas calientes y, por último, al lado derecho de la página, aparece el título "Sexi correo", donde, por medio de correos electrónico, los lectores envían preguntas o piden consejos sobre el desempeño sexual que son respondidos en la sección. “... El asunto es que soy homosexual y cada vez que tengo relaciones anales sangro mucho... ¿qué pasa?", "Mi novia abortó y está muy deprimida y no sé qué hacer".

Farándula: aquí los lectores se encuentran con el mundo light, por medio de 
Lo impactante de El Espacio obedece en gran parte a sus titulares, en color rojo, siempre en admiración, apelan a una suerte de teaser, que involucra al lector con la noticia, con el acontecimiento.

Además de configurar escenarios propios de los sectores populares, esos que en los periódicos oficiales han sido relegados a la caridad. entrevistas o simples notas: "Angelina Jolie se retira del cine", "Otros aires, y su tango electrónico", "John Dee y la Sonora de Barú, homenaje a un grande, "La cantante Noelia, ¡en contra de la noticia!”.

Juan sin Miedo: es un breviario en el que las frases son contundentes y sarcásticas: "A sus 21 años tiene un kilometraje impresionante; la antioqueña se pegó la confundida de su vida”. La frase está acompañada de una fotografía en plano general, de una mujer semidesnuda, siempre en diferentes locaciones como en una sala, en el patio de una casa, en una piscina, o en una oficina.

Crucigrama: espacio dedicado al desafío intelectual de los lectores, allí aparece en forma pedagógica, una manera de construir un saber universal pues sus temáticas son historia, geografía, literatura, gramática, entre otros.

Los ítem enunciados siempre están apoyados por imágenes en las que predominan los planos generales y los planos medios dando sensaciones de totalidad y diálogo, pues esa es la función de estos planos.

Otro dato que se debe tener en cuenta en la construcción cromática del periódico es el predominio de los colores rojo, azul y negro; los dos primeros hacen parte de lo que se podría denominar las noticias "fuertes", pues todas las noticias que poseen impacto semántico están en estos dos colores; el resto de noticias están en negro. Por otro lado, las imágenes periodísticas poseen una estructura similar. Las noticias de gran impacto, están en color; es decir, aquellas que definen la intensidad de la noticia. Por ello podemos afirmar que los colores cumplen una función imperativa en la noticia.
La lectura: “¡Claro!, es un periódico que habla de esas cosas que los otros no dicen como las muertes, las mujeres y sobre todo la vaina esa del sexo, me hace reír mucho" (Testimonio de un vigilante).

\section{Los titulares}

Lo impactante de El Espacio obedece en gran parte a sus titulares, en color rojo, siempre en admiración, apelan a una suerte de teaser, que involucra al lector con la noticia, con el acontecimiento. Además de configurar escenarios propios de los sectores populares, esos que en los periódicos oficiales han sido relegados a la caridad.

\section{"iPelea a machete por celos!"}

El titular sugiere la posibilidad de encontrar en el melodrama la estrategia misma que sustenta la noticia; los celos siempre han sido tema no solo de la información, también hacen parte de la literatura popular. Ellos son instrumento de contienda por medio de la historia fantástica, la que aún hoy palpita en el tejido de lo popular. El instrumento de contienda define los actores de la noticia, en tanto el machete hace parte de la masa que en la historia ha negado la razón y los diálogos como forma de resolución. El machete, el "busetero", el vendedor de abastos, el celador... el titular presenta un cuerpo que hace parte del cotidiano vivir, ese cuerpo ritualizado en los barrios populares y marginales.

\section{"ilnquilino abusador!"}

El inquilinato hace parte del rebusque, a él llegan personas diversas, con hábitos y prácticas sociales diferentes; allí, en el inquilinato, se descubre lo heterogéneo, la alteridad de la sociedad. El inquilino es 
aquel que con estrategias persuasivas entra en un espacio de anonimato, de todos y de nadie para cometer un "abuso". Leo la noticia: "El inquilino violó a un niño”. El abusador es diferente al violador, ¿por qué ese giro semántico? Porque para el periódico solo se puede abusar de un cuerpo infantil, de un niño. Se valida desde allí un proceder, una forma de ser propia de los sujetos populares, de un cuerpo dispuesto a trasgredir el estatuto de convivencia social.

\section{"iloco con un arma!"}

La locura organiza el mapa de lo social. Es la enfermedad por excelencia de las clases populares. El loco, ese que deambula las calles, que con su discurso y su acción asusta, intimida. Un arma, extrañamente los celos hacen parte del ejercicio cotidiano que se cuenta en la noticia. No es loco, es celoso, o tal vez los celos son una patología de lo popular. Celos, armas, muerte, son vectores que cartografían lo popular como forma de la cotidianidad. Loco, enfermo de amor, que hace lo imposible para saciar sus anhelos, sus frustraciones sentimentales.

\section{"iPobre obrero!"}

La figura de lo popular. El obrero, ese que trabaja por contratos temporales de sol a sol con el sudor de su frente se consigue lo del diario vivir. El obrero es quien ejerce los trabajos de construcción o albañilería. El obrero se le "mide" a lo que sea. Es un cuerpo ejemplo de lo popular. Es él un modelo arquetípico tanto en lo moral como en lo sentimental. Y, justamente, la noticia así lo presenta. Un cuerpo éticamente construido para modelar las acciones laborales.

\section{Las imágenes}

Las fotografías publicadas en El Espacio, que son sujeto de análisis en este texto, pueden consultarse en los siguientes vínculos:

Imagen 1. http://i47.tinypic.com/xd6y47.jpg Imagen 2. http://i46.tinypic.com/2a9cdp3.jpg Imagen 3. http://i50.tinypic.com/1f7qe8.jpg Imagen 4. http://i46.tinypic.com/14wf75x.jpg Imagen 5. http://i47.tinypic.com/28j8zm0.jpg

Lo visual es la definición de la contemporaneidad. Las imágenes empiezan a generar el imperio de los signos totalizantes, con los cuales no somos alienados o burlados, sino conquistados por la solicitud persistente de hablarnos, de hacernos ver. Esa conquista debe articular "estrategias de seducción" con las cuales los seducidos nos identificamos. Así toda imagen más que entrar en un juego de "reproducción del referente", debe "mostrar" cómo se representa el objeto, cómo se construye y, sobre todo, cómo se está representando la porción de realidad a la que alude o presenta.

Toda imagen, en tanto signo, posee en su interior una suerte de valer, por lo que representa, posee una historia que se inscribe en las transformaciones de un cuerpo social y una economía. Esto debe comprenderse como un proceso dinámico, en donde factores externos a la imagen delimitan su desciframiento, su comprensión; "las formas del signo están determinadas ante todo tanto por la organización social de los hombres como por las condiciones más inmediatas de su interacción" (Voloshinov: 1992). De esta forma, la suerte del signo se orienta por las vivaces fuerzas de la cultura, permitiendo entender tanto el signo, como los factores que permitieron la aparición de ese signo. 
En este orden de ideas, se podría pensar que lo visual construye su propia narrativa, su estructura de fascinación con la que nos insertamos en el juego narrativo de la sociedad mediática. Por medio de la imagen del periódico El Espacio se exhibe y se consume una sociedad, una manera de ver y de sentir lo popular: es el llanto, el sufrimiento por lo pasional, la muerte, la resistencia y sobre todo, lo pornográfico. Es una sociedad que le da importancia al detalle, a la fragmentación del cuerpo.

Al mismo tiempo lo visual requiere de una mirada, esta no es solo una manera de aprehensión, de conceptualizar y abstraer la realidad; no, es un mecanismo de producción que permite cartografiar los reconocimientos propios de una cultura. El mirar es un constructo de producción semiotizante de carácter histórico (diacrónico), que hace ver y deja ver cómo se refleja la cultura y sus transformaciones en sus maneras de representación. Por ello, es distancia entre el objeto y el observador, distancia significante de los valores culturales con los que se representa un objeto.

Como plantea Umberto Eco (2002), la mirada es un instrumento particular de la cultura, que relaciona, no objetos a significados estables, sino materiales significantes a unidades culturales, es decir, a tramados de desciframiento visual que desafían (en el acto de la creación), cuestionan y vehiculizan maneras singulares de producción, haciendo parte de un acervo de conocimientos de los sujetos sociales.

Cada una de las imágenes presentadas posee una misma lógica: la polarización de lo fotografiado para poder construir un diálogo extra periodístico, en otras palabras, la conversación entre los sujetos sociales. Entiendo la polarización como ese estado donde lo maniqueo es fuente de celebración; la muerte, o la vida representada con colores y poses; la salvación o la perdición mediante objetos cristianos; lo esperado y lo no esperado, en gestos y utensilios; bustos voluptuosos y no voluptuosos en la representación de la mujer. Todo ello es una representación de la cotidianidad, una invención de lo real que vincula y acerca. En ese bosque visual es donde la lógica de lo popular aparece para reivindicar una manera propia de construir la cartografía de una de las tantas realidades.

En la Imagen 1, se puede observar cómo la pose del infante determina el carácter propio de la intensión visual. En una manifestación son los niños los que deben sufrir las consecuencias. El contexto visual en el que se encuentran los actores, disloca el referente de lo cándido para ubicarlo en lo malicioso, en lo escabroso. Lo realmente importante de esta imagen es comprender la inocencia como espacio narrativo que se va a socavar, es fuente de dispositivos que activan la conversación cotidiana.

En la Imagen 2 lo importante es el gesto como sistema de representación del dolor, utilizando como instrumento significante la mirada extraviada, en un espacio que escapa tanto a lo periodístico como a lo estético, para ubicarse en el escenario ficcional de la narración. Los anillos que se ven en sus manos demuestran el carácter sincrético de lo popular; el anillo ha sido un objeto de distinción social, y entre más anillos (en la lógica popular, eso que Geerzt denominó el sentido común) más prestigio. Así no solo se construye una idea del duelo, sino de prestigio y feminidad. Al lado izquierdo se muestra una niña sonriente... se perpetúa un estado propio que define la niñez, la felicidad 
desde la sonrisa, para ser un instrumento de activación narrativa.

Las Imágenes 3 y 4 construyen un cuerpo que puede ser visto como lo erótico en lo popular. Eso erótico puede ser definido como pornografía en tanto que muestra y ofrece el cuerpo, objeto de deseo a la mirada colectiva. Ese cuerpo construye una forma de ser recorrido pues lo importante no es el cuerpo, sino los senos de la mujer junto con los glúteos y el color del cabello: rubias y pelinegras, tetonas y culonas son los íconos que el periódico presenta; emerge en lo visual uno de los modelos de la mujer como imagen social en tanto hecho modelo estereotipado. En estas imágenes emergen lo cliché visual, siempre mostrar lo mismo garantiza que se modelen los preceptos del cuerpo femenino.

En la Imagen 5 la mutilación hace parte del elemento que ayuda a configurar una idea de lo popular como sufrimiento: allí el hombre fotografiado ha perdido sus manos y se encuentra en la lucha con "la muerte"; los objetos presentes permiten reconstruir el contexto que valida la imagen como hecho veraz, junto a eso vuelve a sugerirse el gesto y la pose como sistema significante de sentido social. Creo adecuado decir que al buscar algunas cifras sobre índices de mutilados por pólvora o en riñas, curiosamente son las clases medias las más damnificadas; pero en el sentido cultural son las populares las que "sufren ese cruel destino".

Todo es posible para las imágenes del periódico, lo importante es entrar en los dispositivos de reconocimiento popular, construir un vínculo que permita reconocer y reconocerse: en la imagen de El Espacio, el hombre, el mundo y el sentimiento tienen un matiz cristiano que se articula de manera acertada con la idea de fe que se posee en el sistema de creencias de las clases populares. Toda imagen aparece como un hecho revelador, misterioso y hasta milagroso, por ello, su carácter estético no depende de la presentación de lo fotografiado, sino de lo no explícito: el interés estético radica en su capacidad de dilatar lo visual para insertarlo en un juego de opiniones que acaudalan el discurso social popular.

La resistencia y la crisis del periódico El Espacio está en la forma como se usan las notas informativas; está en la narración cotidiana y no en el mismo informativo; el periódico sigue una lógica que se articula en lo moral-ético-religioso, que es justo lo que propone lo popular: un sistema de resistencia ante los discursos hegemónicos de los periódicos “oficiales”. El Espacio captura la sensibilidad de lo popular por medio de frases cliché, imágenes de cajón y una estética de lo no visual se acerca a la representación del sufrimiento, dolor, riqueza o pobreza que posee lo popular.

Así, lo que "está en juego es una cuestión de códigos culturales de acceso, de apropiación y uso de los lenguajes específicos" (Rey, 2008:120), que se presentan en cada una de las secciones del periódico y que se repiten de manera permanente cuando es consumida en el acto de la significación. Entonces, el periódico deja de ser un objeto cerrado, natural (si el concepto lo permite) para ser decorado e investido de complacencias estéticas, políticas y narrativas que develan el funcionamiento de la representación, de la invención del mundo. De esta forma, descrito esto, se puede percibir cómo la imagen llega a ser comprendida en cuanto representación.
Toda imagen aparece como un hecho revelador, misterioso y hasta milagroso, por ello, su carácter estético no depende de la presentación de lo fotografiado, sino de lo no explícito: el interés estético radica en $s u$ capacidad de dilatar lo visual para insertarlo en un juego de opiniones que acaudalan el discurso social popular. 


\section{Bibliografía}

1. Barthes, Roland. (1980a). Mitologías. Madrid: Siglo XXI.

2. Barthes, Roland. (1980b). La cámara lúcida. Barcelona: Paidós comunicaciones.

3. Barthes, Roland. (1977). Fragmentos de un discurso amoroso. Madrid: Siglo XXI. Barthes, Roland. (1975). Lo obvio y lo obtuso. Madrid: Siglo XXI.

4. Barbero, Jesús Martín. (2005). Oficio de cartógrafo. Bogotá: Convenio Andrés Bello.

5. Barbero, Jesús Martín. (2003). De los medios a las mediaciones, Bogotá: Convenio Andrés Bello.

6. Baudrillard, Jean. (1990). La transparencia del mal. Barcelona: Anagrama.

7. Baudrillard, Jean. (1964). El sistema de los objetos. México: Siglo XXI.

8. De Certeau, Michel. (1999). La invención de lo cotidiano. México: Universidad Iberoamericana.

9. Eco, Umberto. (2002). Tratado de semiótica general. México: Debolsillo.

10. Eco, Umberto. (2002). Apocalípticos e integrados. México: Debolsillo.

11. Eco, Umberto. (2002). El hombre de masas. México: Debolsillo.

12. González Requena, Jesús. El spot publicitario. Madrid: Cátedra.

13. Grupo U. (1993). Tratado del signo visual. Madrid: Cátedra.

14. Piscitelli, Alejandro. (1998). Post/Televisión. Barcelona: Paidós Contextos.

15. Rey, Germán. (2006). Tramas de la Cultura. Bogotá: Convenio Andrés Bello, CAB

16. Barbero, Jesús M. (2008). Revista Posiciones. Universidad del Valle, abril (2) Cali.

17. Rincón, Omar. (2006). Narrativas mediáticas. Barcelona: Gedisa.

18. Silva, Armando (1998). Álbum de familia. Bogotá: Norma.

19. Traversa, Oscar. (1998). Cuerpos de papel. Barcelona: Gedisa.

20. Thompson, John B. (1994). Los media y la modernidad. Barcelona: Gedisa.

21. Voloshinov, Valentín (1992). Marxismo y filosofía del lenguaje. Madrid: Editorial Alianza. 